This item was submitted to Loughborough's Research Repository by the author.

Items in Figshare are protected by copyright, with all rights reserved, unless otherwise indicated.

\title{
Shear behaviour of sprayed concrete
}

PLEASE CITE THE PUBLISHED VERSION

https://doi.org/10.1016/j.conbuildmat.2016.07.050

\section{PUBLISHER}

(c) Elsevier

\section{VERSION}

AM (Accepted Manuscript)

\section{PUBLISHER STATEMENT}

This work is made available according to the conditions of the Creative Commons Attribution-NonCommercialNoDerivatives 4.0 International (CC BY-NC-ND 4.0) licence. Full details of this licence are available at: https://creativecommons.org/licenses/by-nc-nd/4.0/

\section{LICENCE}

CC BY-NC-ND 4.0

\section{REPOSITORY RECORD}

Garcia, T., Ana Blanco, and Sergio H. Cavalaro. 2019. "Shear Behaviour of Sprayed Concrete". figshare. https://hdl.handle.net/2134/32296. 
${ }^{a}$ Department of Civil and Environmental Engineering, Universitat Politècnica de Catalunya-BarcelonaTech, UPC,

$4 \quad$ Jordi Girona 1-3, 08034 Barcelona, Spain.

* Corresponding author. Tel.: +34-93-401-7354; fax: +34-93-401-1036; e-mail: tomas.garcia@upc.edu

Abstract

Shear in sprayed concrete (SC) may govern the design criteria in certain applications subjected to seismic loads or in bolted areas. However, it has been scarcely studied given the complexity of reproducing the production conditions in the laboratory and the lack of standardized tests. The paper focuses on the shear characterization of SC using a shear test compatible with the sample production. For that, an experimental program is performed analysing the influence of several parameters and comparing the results to those of a reference concrete. Furthermore, the outcome validates the shear test selected for the characterization of SC.

Keywords: sprayed concrete, shear, Luong test, set-accelerator

\section{INTRODUCTION}

16 Sprayed concrete (SC) is a material extensively used worldwide for underground support, slope 17 stabilization and the construction of domes, façades or reservoirs. Despite that, it has been scarcely studied under controlled laboratory conditions if compared with other types of concrete. The main reason for that is the difficulty to emulate in laboratory the production conditions found in practice, which would imply the use of big facilities and equipment to spray and pump concrete. Among the properties of SC that require further studies is the shear behaviour. Especially in elements subjected to seismic loads or in bolted areas, the shear strength might play an important role on the ultimate limit state verifications, as well as on the partial or complete failure of the structure. 
25 The formulations available nowadays in codes and guidelines to conduct the structural 26 verification in shear are derived from extensive studies on either conventional or high 27 performance concrete. Even though all these types of concrete share similarities in terms of composition, relevant differences arise due to the casting procedure in the case of SC. For instance, to assure a good pumpability and decrease the incidence of blockages, a reduction of the relative amount and the maximum size of coarse aggregate is necessary in SC mixes (Agulló et al. 2009). During the spraying process, the introduction of compressed air and set-accelerator admixtures at the nozzle modify the microstructure of the cement paste, affecting the hydrated compounds formed and leading to higher porosity (Galobardes et al. 2014, Salvador et al. 2016a, Salvador et al. 2016b). Moreover, part of the components rebound when the concrete impacts against the substrate. This rebound is higher for bigger particles, like the coarse aggregates. In other words, an additional reduction on the content of this fraction is observed.

Studies on conventional concrete show that aggregate interlock is one of the main mechanisms governing the shear behaviour. Consequently, the higher porosity of the concrete matrix together with the smaller aggregate size and content must affect the shear behaviour. In this context, the direct use of formulation for conventional concrete for the design of SC elements might lead to unsafe predictions. In order to overcome this drawback and promote the efficient use of SC, it is necessary to conduct rigorous experimental studies on the shear behaviour of the material in comparison with equivalent conventional concrete.

44 The assessment of pure shear behaviour of concrete is a complex task. No standardized tests are available and most of the tests found in the literature require special sample preparation and setups hardly compatible with the execution of SC structures. The selection and adaptation of a

47 simple shear test to these conditions might represent an additional contribution since the results obtained could be used for the quality control of the variability of the material.

49 Taking that into account, the primary objective of this paper is to evaluate the shear behaviour of SC under controlled laboratory conditions and in comparison with a reference concrete 
51 (REF). The secondary objective of this study is to define a simple test to evaluate the shear

52 behaviour in SC, considering the condition found in most worksites. For that, first an in depth

53 evaluation of the setup of the shear tests available in the literature is performed. Then, an

54 experimental program with a reference concrete mix (manually poured) is conducted to define

55 the parameters used in the test and to obtain reference values for the comparison with SC. Next,

56 an experimental program with SC that is sprayed in laboratory and characterized with the

57 proposed test setup. The influence of the porosity, of the humidity and of the type or content of

58 set-accelerator on the microstructure are evaluated. The results not only shed light on the

59 reductions expected on the shear behaviour in comparison with the reference concrete mix, but

60 also validate a test setup for future studies or for the quality control.

\section{2. SHEAR CHARACTERIZATION TESTS}

62 A common issue in these tests is the difficulty to achieve a situation of pure shear. Most of the 63 setups available in the literature present an eccentricity in the application of the load. As a result, other phenomena such as bending may also appear, leading to a combination of tensile and shear failure. In order to reduce variability and obtain reliable results, it is important to select tests that minimize this effect. Table 1 summarizes the main shear tests reported in the

67 literature.

68 The push-off tests is the most frequently used to characterize shear (Barr, 1987). They are 69 usually conducted on Z-shaped prism or cylinders with two notches in opposed faces that resemble two L-shaped blocks joined by a common plane. A compression load applied at the top and bottom surfaces generates shear stresses in the common plane. The setup may vary depending on the geometry of the specimens and the location of the notches (Barr, 1987; Allos, 1989). Other procedures reported in the literature are performed in deep beams or panels (Barr, 1987; Shah et al., 1995) with aligned or eccentric notches on the top and bottom surfaces (in some cases the notches are only on the bottom surface) that are subjected to punching. 
76 The Iosipescu shear test was originally proposed for metals and welded joints (Iosipescu 1967).

77 Barr (1990) and Schlangen (1993) applied it to concrete and concluded that a failure mode with

78 mixed shear and tensile stress was normally observed. Alternatively, the shear test proposed in

79 the Japanese recommendations JSCE-SF6 (JSCE 1990) is conducted on a beam with two

80 notches. The load is applied by a steel block with two wedges close to the mouth of the notches,

81 generating a stress field (Mirsayah and Banthia, 2002) that favors the shear failure. The LCB

82 test was developed to evaluate the bond between pavements layers of bituminous materials

83 through the shear strength (Miro et al. 2003, Miro et al. 2006) based on the Spanish standard

84 NLT-328/08 (CEDEX 2008). A study performed by Segura and Aguado (2012) to assess the

85 bond between SC and conventional concrete with the LCB showed that a mixed failure was also

86 commonly observed.

Table 1. Summary of shear characterization tests

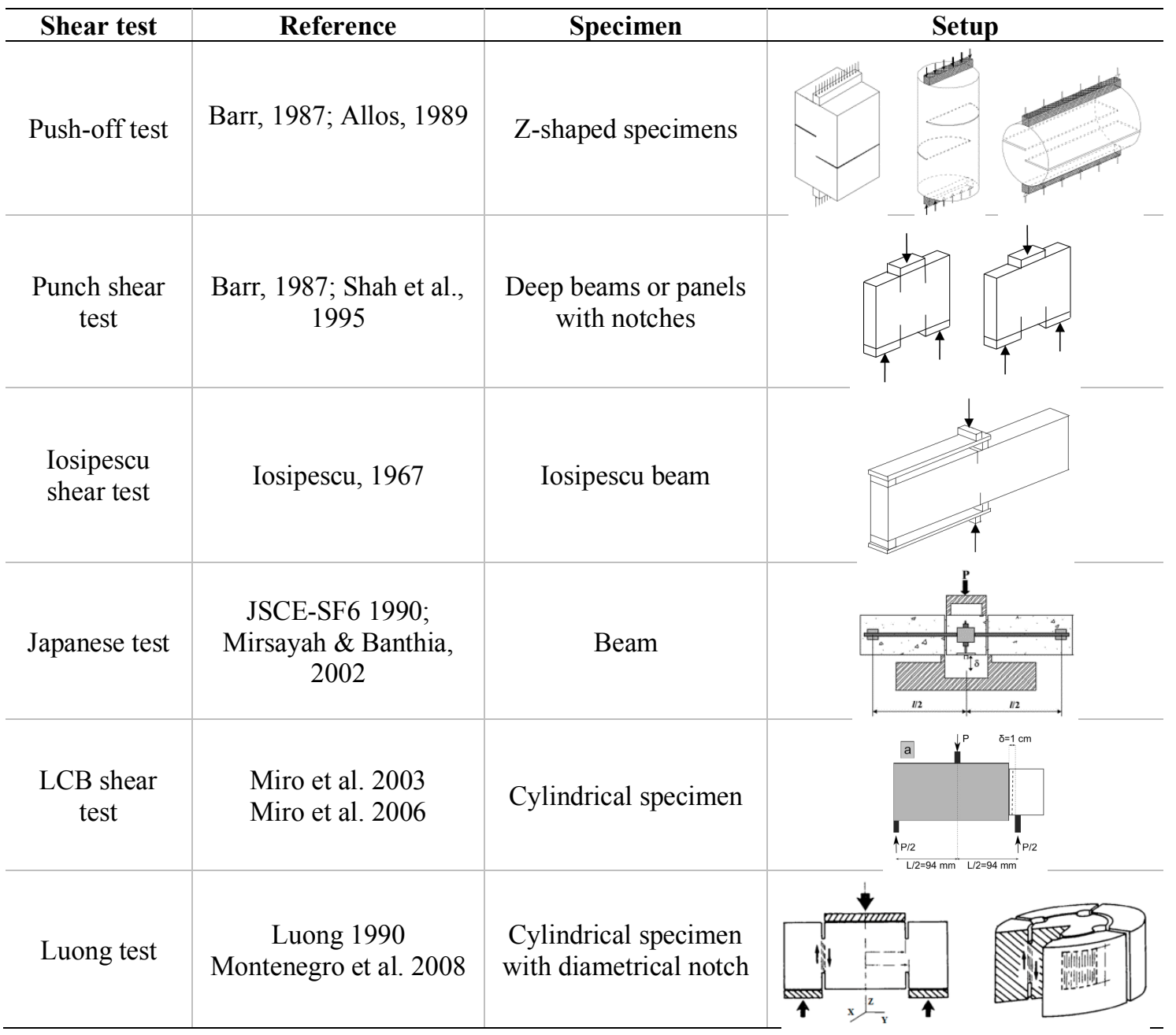


88 The Luong test is performed on a cylindrical specimen (100 $\mathrm{mm}$ of diameter) with a relatively 89 small height $(40 \mathrm{~mm}$ ) and concentric notches (Luong 1990). The notches may be executed with 90 the same drilling machine used for the extraction of the specimens, changing the core bit for 91 another with smaller diameter. The load is applied in the central area of the top surface (inside 92 the perimeter of the notch) and in the external area of the bottom surface (outside the perimeter of the notch), as indicated in Table 1. In the original setup, the load is distributed over the whole inner and outer surface of the specimen, which might induce additional eccentricity. Montenegro et al. (2008) successfully applied the test to characterize shear behaviour of conventional concrete under a triaxial stress state.

For the selection of the most adequate test, certain limitations with regards to the production of SC specimens have to be considered. The spraying of an extensive surface is usually necessary to assure representativeness and to avoid the characterization of zones close to the borders, which a more likely to present imperfections. The tests are directly applied to panels or to specimens such as beams or cylinders extracted from the sprayed zone. Particularly in the case of beams, the extraction procedure entails the additional difficulty of keeping the faces of the specimen parallel. Another potential inconvenient is the high weight of the beams, which compromise their manipulation and the number of tests performed. On the contrary, drilled cylinders are easier to obtain, requiring simple specimen preparation procedures as the polishing or cutting of both ends. Moreover, the extracted cylinders are easier to manipulate and allow the execution of more tests for the same panel or sprayed zone. Based on the exposed previously, tests that require cylindrical specimens are selected.

From all the methods presented in Table 1 that use this shape of specimen, the LCB is disregarded since it requires cylinders with a height of more than $12 \mathrm{~cm}$, which is bigger than the thickness of the SC layer of some applications. Likewise, the push-off test is disregarded due to the difficulties of performing perfectly parallel and coinciding notches. In this context, the Luong test was selected since it allows the characterization of cylinders with less than $10 \mathrm{~cm}$ of length implying a simpler sample preparation procedure. 


\subsection{Methodology}

117 Given that the Luong test is not standardized and the literature does not report the influence of 118 parameters of the test setup on the results, a preliminary experimental study is conducted to define the most adequate configuration. Considering the difficulties to obtain sprayed concrete specimens in the laboratory, this preliminary study is performed on a reference concrete (REF) that is manually poured. This will also provide reference values for the comparison with equivalent sprayed mixes. After defining the most adequate setup, a second experimental program is conducted on SC.

\subsubsection{Materials, concrete mix and basic properties}

The concrete mix used to cast the specimens was designed to reproduce the typical composition employed in wet-mix sprayed concrete. For this reason, a water/cement ratio (w/c) of 0.45 and a cement content of $425 \mathrm{~kg} / \mathrm{m}^{3}$ were defined. The aggregates were selected according to EN12620:2002 (CEN 2002), considering the limits induced by the spraying pump. The details of the concrete mix are presented in Table 2.

Table 2. Concrete mix

\begin{tabular}{lccc}
\hline \multirow{2}{*}{ Materials } & \multicolumn{3}{c}{ Content $\left(\mathbf{k g} / \mathbf{m}^{3}\right)$} \\
\cline { 2 - 4 } & REF & $\begin{array}{c}\text { SC 1 } \\
\text { (see section 4.1.4) }\end{array}$ & $\begin{array}{c}\text { SC 2 } \\
\text { (see section 4.1.4) }\end{array}$ \\
\hline Cement CEM I-42.5R & 425 & 425 & 425 \\
Water & 190 & 190 & 190 \\
Sand (0/2 mm) & 380 & 380 & 380 \\
Sand (0/5 mm) & 900 & 900 & 900 \\
Gravel (5/12 mm) & 380 & 380 & 380 \\
Superplasticizer (Polycarboxylate based) & 4.25 & 4.25 & 4.25 \\
Set-accelerator A1 & - & $5-7 \%$ bcw & - \\
Set-accelerator A2 & \multicolumn{3}{c}{-} \\
\hline
\end{tabular}

133 Cylindrical specimens of $100 \mathrm{~mm}$ of diameter and $200 \mathrm{~mm}$ of height were produced to evaluate the modulus of elasticity according to EN 12390-13:2014 (CEN 2014) and the compressive strength as indicated in EN 12390-3:2009 (CEN 2009). The dry density and the porosity were 
measured according with the EN 12390-7:2009 (CEN 2009) in 7 specimens. Cylinders with a diameter of $150 \mathrm{~mm}$ and a height of $300 \mathrm{~mm}$ were cast to obtain the samples for the Luong test. All specimens were moist cured under a plastic sheet for 24 hours until their removal from the moulds and then were kept in a curing room at $20 \pm 2{ }^{\circ} \mathrm{C}$ and $95 \%$ of relative humidity. Table 3 presents the average basic properties at 28 days and their coefficient of variation for the reference concrete.

Table 3. Basic properties of the reference concrete (REF)

\begin{tabular}{c|l|c|c}
\hline \multicolumn{2}{c}{ Properties } & Sample & Average (CV) \\
\hline \multirow{2}{*}{ Mechanical properties } & Compressive strength (MPa) & $\varnothing 100 \times 200 \mathrm{~mm}$ & $54.3(10.5 \%)$ \\
& Modulus of elasticity (GPa) & $\emptyset 100 \times 200 \mathrm{~mm}$ & $33.4(2.5 \%)$ \\
\hline \multirow{2}{*}{ Physical properties } & Dry density $\left(\mathrm{g} / \mathrm{cm}^{3}\right)$ & Cores from the & $2.18(0.04 \%)$ \\
& Porosity (\%) & shear specimens & $10.8(15.9 \%)$ \\
\hline
\end{tabular}

\subsubsection{Preparation of the samples}

The REF cylinders for the Luong Test were cut into smaller samples with a diametrical notch. Each sample was identified according to their position in the original REF cylinder. The dimensions of the samples selected for the experimental program are $150 \mathrm{~mm}$ of diameter and $60 \mathrm{~mm}$ of height. Notice that this height differs from the original specimen proposed by Luong (1990). Such modification was adopted to increase the confinement and the area characterized in the test, also respecting the minimum thickness usually found in sprayed layers. The surfaces of the sample obtained after cutting were polished with a diamond blade in order to assure their parallelism. Finally, a notch with a depth of $10 \mathrm{~mm}$ was executed perpendicular to the top and bottom surface of each sample. The diameter of the notch is a variable of this study that is discussed in section 3.4.

\subsubsection{Test setup}

An eccentric load is applied by a hydraulic press at the top and bottom surfaces of the sample by means of two circular steel pieces. The load at the top is located in the external area (outside the perimeter of the notch), whereas the load at the bottom is located in the internal area (inside the 
perimeter of the notch), as shown in Fig.1. To capture the complete load-displacement curve, a constant displacement rate of the piston press is applied. The shear strength is obtained from the ratio between the maximum load reached during the test and the resistant area (see Fig. 1b). For notation purposes, the height of the notched section will be referred to as effective height.

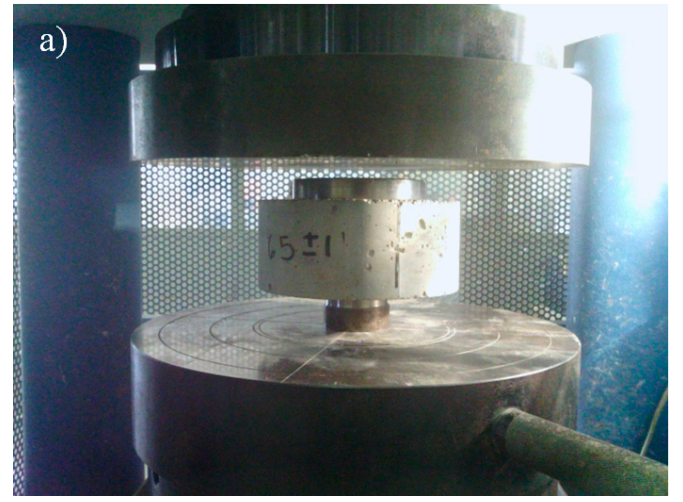

b)

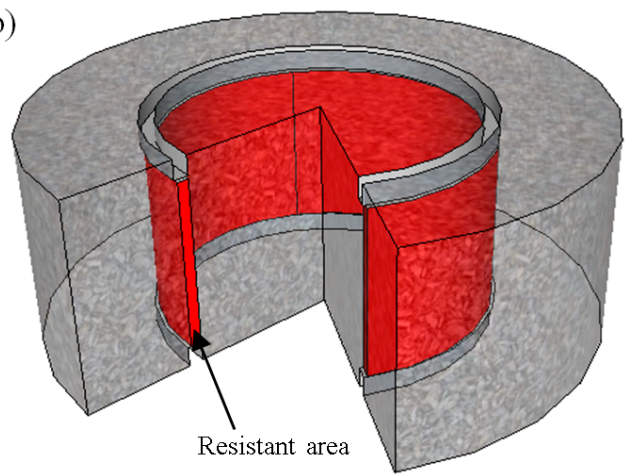

Fig. 1 a) Location of the circular steel pieces and b) shear resistant area

The first stage of the test is characterized by a linear-elastic behaviour. When the shear strength of concrete is reached, a crack along the plane of the notch appears and a cylinder is formed in the internal area of the notch. At this stage, the aggregate interlock is the main mechanism governing the shear behaviour. As the stresses generated by the application of load increase and radial cracks appear in the external concrete crown. Notice that for a pure shear failure to take place, the fracture surface in the notched plane should be as vertical as possible.

\subsubsection{Selection of parameters}

Three parameters of the test setup were selected in order to determine their influence on the results and, subsequently, to identify which values are more suitable. The selection of these values was done in successive phases as shown in Fig.2. The first parameter of the test setup evaluated was the displacement rate given its potential influence over the control of the test and over the maximum load resisted by the specimen. Displacement rates of $0.1 \mathrm{~mm} / \mathrm{s}, 0.2 \mathrm{~mm} / \mathrm{s}$ or $0.4 \mathrm{~mm} / \mathrm{s}$ were used considering other studies on shear. 


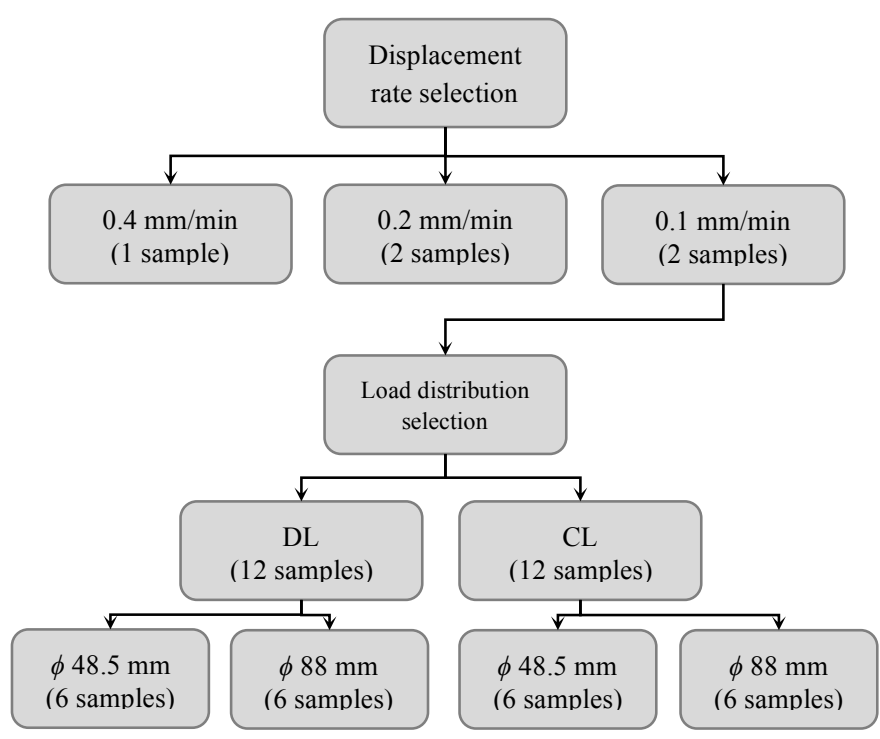

180 The second parameter was the loading area due to its repercussion in the eccentricity and,

181 consequently, the failure mode. As shown in Fig.3, two load configurations were applied:

182 distributed or concentrated. In the distributed, the load is applied over the whole external area of

183 the notch in the upper surface and the whole internal area of the notch in the bottom surface (see

184 Fig.3a). In the concentrated, loads are located in an area of $10 \mathrm{~mm}$ of thickness outside the

185 perimeter in the top surface and inside the perimeter in the bottom surface (see Fig.3b).

186

187 Even though the majority of the studies from the literature with the Luong test use the 188 distributed load, it might induce higher eccentricities than the concentrated load. Consequently, 189 mixed stress states are more likely to occur in the former. In both cases, the load was applied 190 with two steel cylindrical plates with $3 \mathrm{~cm}$ of height in order to avoid deformations that could 191 affect the results. 
a)

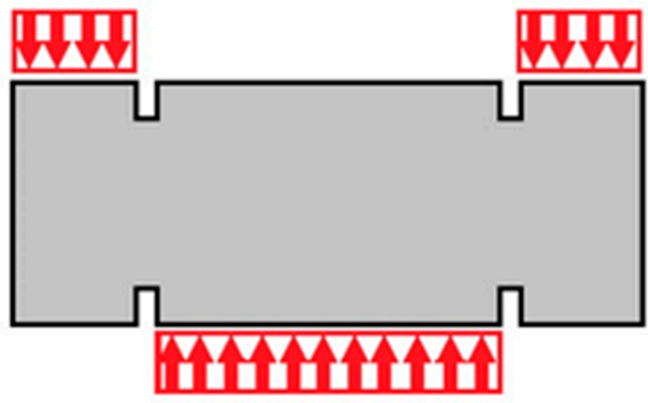

b)

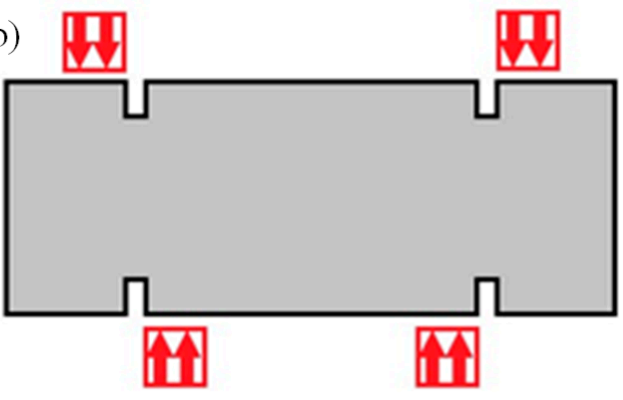

Fig.3 Loading area: a) distributed and b) concentrated

The third parameter was the diameter of the notch. As this diameter increases, the crown of concrete outside the perimeter of the notch becomes smaller, thus reducing the confinement provided to the failure plane and affecting the test results. Based on the typical dimensions of commercial drills available, the diameters of $48.5 \mathrm{~mm}$ and $88 \mathrm{~mm}$ were chosen. Both values ensure that the thickness of the external concrete crown is at least two times bigger than the maximum aggregate size in the mix.

The notation used to designate the samples corresponds to the main parameters selected for the study. Hence, the notation of each sample indicates the type of concrete (REF or SC), the diameter of the notch $(48.5 \mathrm{~mm}$ and $88 \mathrm{~mm})$, the displacement rate $(0.1 \mathrm{~mm} / \mathrm{min}, 0.2 \mathrm{~mm} / \mathrm{min}$ or $0.4 \mathrm{~mm} / \mathrm{min}$ ) and the load application area (distributed loads or DL and concentrated loads or CL). A final number is added to the notation to differentiate between samples from the same type (e.g. REF_88_0.1_CL_1 and REF_88_0.1_CL_2).

\subsection{Results and analysis}

\subsubsection{Influence of the displacement rate}

The displacement rate was evaluated by testing 5 specimens with a notch of $48.5 \mathrm{~mm}$ of diameter and a distributed load. Two specimens were tested at each displacement rate, except for the case of $0.4 \mathrm{~mm} / \mathrm{min}$ due to the evident problems observed throughout the test (see Fig.4). Fig.4 presents the stress-displacement curves for each of the samples as well as the average values of shear strength depending on the displacement rate. 


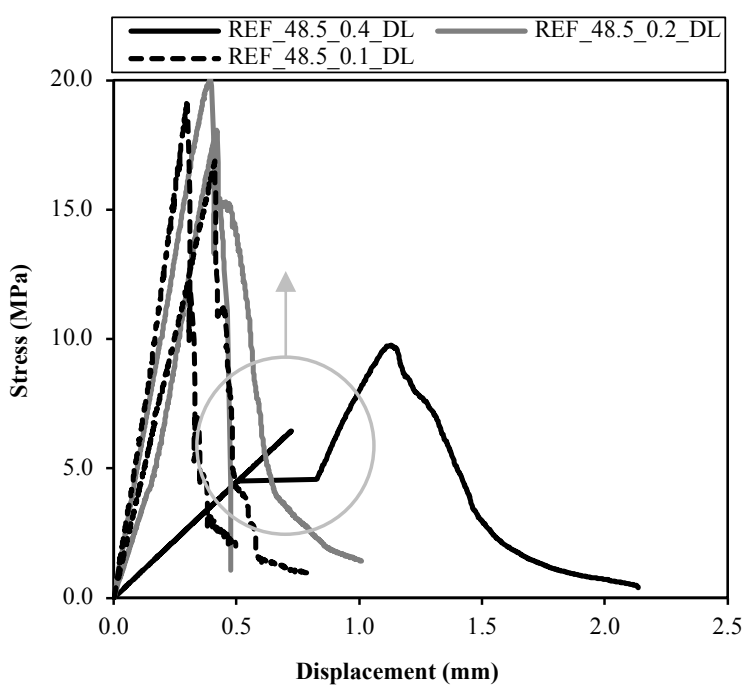

217 In general, the curves exhibit a first stretch of a linear-elastic behaviour until the shear strength 218 of the concrete is reached. At this moment, a circumferential crack appears along the perimeter 219 of the notch, thus leading to a loss of stiffness that is represented in the curves of Fig. 4 by a sudden drop in the stress. Subsequently, the aggregate interlock mechanism starts providing a residual strength that is represented by the last stretch of the curves. This stage is characterized by a progressive reduction of in the value of stress.

223 It is clear that the sample loaded at a displacement rate of $0.4 \mathrm{~mm} / \mathrm{min}$ (REF_48.5_0.4_DL) does not follow the described trend. Instead, it shows a linear behaviour with high values of displacement up to a first peak, after which the stress drops and then increases again up to a second peak. This response indicates that the control of the test at $0.4 \mathrm{~mm} / \mathrm{min}$ was not adequate and that a sequential failure occurred. Conversely, the curves obtained for the samples tested at $0.2 \mathrm{~mm} / \mathrm{min}$ and $0.1 \mathrm{~mm} / \mathrm{min}$ present a similar trend with no significant differences and no evidences of an unsuitable control or failure. displacement rates, the average shear strength increases. Notice that a displacement rate of 0.4 $\mathrm{mm} / \mathrm{min}$ leads to values around $10 \mathrm{MPa}$, whereas when the rate is reduced to $0.2 \mathrm{~mm} / \mathrm{min}$ or 0.1 $\mathrm{mm} / \mathrm{min}$, the strengths increase by $95 \%$ and $83 \%$, respectively. In view of the results obtained, 
both $0.2 \mathrm{~mm} / \mathrm{min}$ and $0.1 \mathrm{~mm} / \mathrm{min}$ could be adopted. In this case, $0.1 \mathrm{~mm} / \mathrm{min}$ is selected to assure an adequate recording of the complete curve, especially in the residual stretch.

\subsubsection{Influence of the load distribution}

237 Based on the previous results, the influence of the load distribution was assessed by testing samples with a displacement rate of $0.1 \mathrm{~mm} / \mathrm{min}$, diameters of the notch of $48.5 \mathrm{~mm}$ and $88 \mathrm{~mm}$ and two load distributions shown in Fig.3. A total of 12 samples were tested, 6 for each case of diameter of notch and load distribution. Table 4 presents the average shear stresses and the corresponding coefficient of variation.

\begin{tabular}{|c|c|c|c|c|c|}
\hline \multirow[b]{2}{*}{ Load } & \multirow[b]{2}{*}{ Specimen } & \multicolumn{2}{|c|}{ Ø48.5 mm } & \multicolumn{2}{|c|}{$088 \mathrm{~mm}$} \\
\hline & & $\begin{array}{c}\text { Shear strength } \\
\text { (MPa) }\end{array}$ & $\begin{array}{c}\text { Average } \\
\text { (CV) }\end{array}$ & $\begin{array}{c}\text { Shear strength } \\
\text { (MPa) }\end{array}$ & $\begin{array}{c}\text { Average } \\
\text { (CV) }\end{array}$ \\
\hline CL & $\begin{array}{l}\text { REF_Ø_01_CL_11 } \\
\text { REF_Ø_01_CL_12 } \\
\text { REF_Ø_01_CL_21 } \\
\text { REF_Ø_01_CL_22 } \\
\text { REF_Ø_01_CL_23 } \\
\text { REF_Ø01_CL 24 }\end{array}$ & $\begin{array}{l}16.78 \\
11.66 \\
10.73 \\
12.44 \\
14.43 \\
17.31\end{array}$ & $\begin{array}{c}13.89 \\
(19.7 \%)\end{array}$ & $\begin{array}{c}10.32 \\
12.54 \\
10.63 \\
7.35 \\
11.70 \\
10.31\end{array}$ & $\begin{array}{c}10.48 \\
(16.9 \%)\end{array}$ \\
\hline DL & $\begin{array}{l}\text { REF_Ø_01_DL_11 } \\
\text { REF_Ø_01_DL_12 } \\
\text { REF_Ø_01_DL_21 } \\
\text { REF_Ø_01_DL_22 } \\
\text { REF_Ø_01_DL_23 } \\
\text { REF ØØ01_DL } 24\end{array}$ & $\begin{array}{l}17.47 \\
16.18 \\
14.27 \\
14.58 \\
14.02 \\
13.63\end{array}$ & $\begin{array}{l}15.03 \\
(9.9 \%)\end{array}$ & $\begin{array}{c}2.47 \\
7.00 \\
7.77 \\
10.04 \\
12.57 \\
11.06\end{array}$ & $\begin{array}{c}9.69 \\
(23.8 \%)\end{array}$ \\
\hline
\end{tabular}

244 The results obtained in Table 4 reveal that the influence of the load distribution depends strongly on the diameter of the notch. For the case of $48.5 \mathrm{~mm}$, the shear strength is $8.2 \%$ higher for the DL than for the CL. In addition, the scatter is significantly smaller for the former.

247 Nevertheless, this behaviour does not apply for the samples with $88 \mathrm{~mm}$ of diameter. In this case, samples with CL exhibit the highest shear strength and smaller scatter. Notice that the highest scatter is obtained for samples of $88 \mathrm{~mm}$ in the DL configuration.

251 In terms of the failure mechanism observed during the test, the DL leads to cracking outside the 
edges of the top surface and progress to the centre of the bottom surface, thus leading to a

254 failure mode affected by eccentricities. Conversely, under concentrated loads, the cracking 255 occurs in the plane of the notch (see Fig.5b) since the tension lines progress from the centre of 256 the top-loading surface to the centre of the bottom-loading surface. This generates almost 257 vertical cracking planes, approaching a failure due to pure shear.

a)
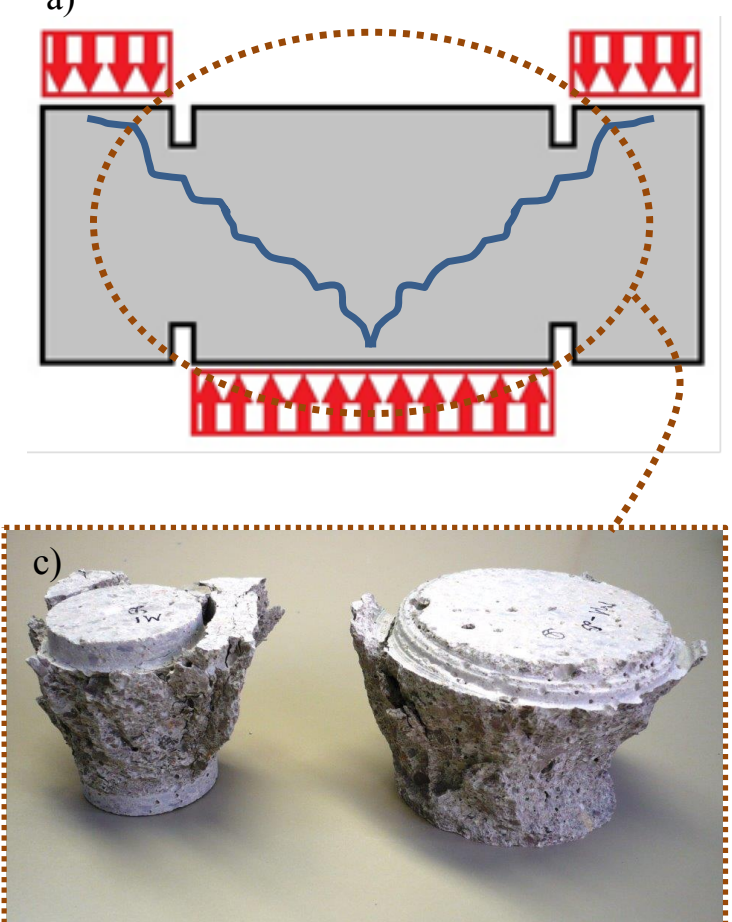

b)

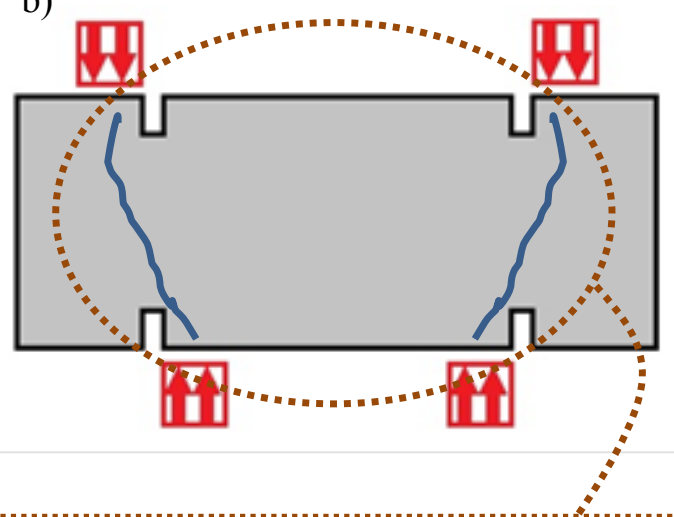

d)

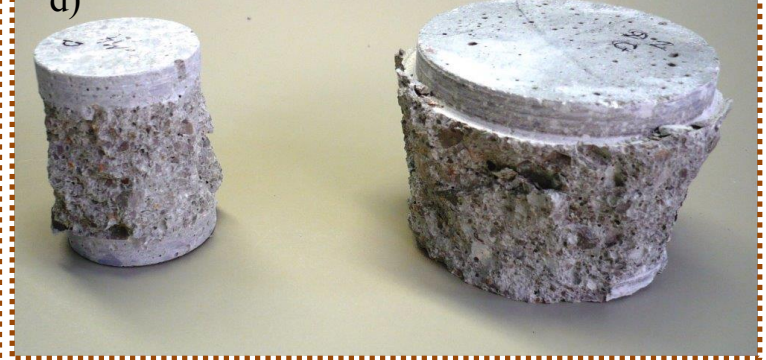

258

Fig. 5 Failure planes in the Luong test: a) distributed load for diameters of $48.5 \mathrm{~mm}$ and $88 \mathrm{~mm}$ and b) concentrated loads for diameters of $48.5 \mathrm{~mm}$ and $88 \mathrm{~mm}$.

The visual inspection of the samples after the test confirms that the setup with concentrated load (CL) yields a mechanism closer to ideal shear failure than that found in case of the setup with distributed load (DL). Therefore, in the second stage of the experimental program, the CL configuration is adopted to evaluate shear of sprayed concrete.

\subsubsection{Influence of the diameter of the notch}

The repercussion of using a diameter of the notch of $48.5 \mathrm{~mm}$ or $88 \mathrm{~mm}$ was evaluated by performing 16 tests with concentrated and distributed loads. The results are included in Table 4. 
270 The samples with a diameter of the notch of $48.5 \mathrm{~mm}$ exhibit higher average shear strength for

271 both load configurations due the bigger confinement provided by the external crown. Notice

272 that the external crown is the volume of concrete outside the perimeter of the notch, which is

273 thicker in the case of the samples with the notch of $48.5 \mathrm{~mm}$. However, despite the results, no

274 conclusive outcome may be obtained from the results on which diameter is more suitable for the

275 performance of the tests. This is due to the high scatter observed in the case of the samples with

$27688 \mathrm{~mm}$ of diameter and distributed load. For that reason, both diameters are further evaluated in

277 the subsequent stages of the experimental program (on SC samples).

\section{EXPERIMENTAL PROGRAM ON SPRAYED CONCRETE}

279

280

\subsection{Methodology}

In previous sections, the parameters associated to the Luong test setup were assessed in conventional concrete cylinders. This section describes the methodology proposed to evaluate the influence of the SC characteristics on the shear behaviour of the material. It is known that the main factors affecting the shear behaviour of concrete are the aggregate and the mortar characteristics. Given the limitations regarding maximum aggregate size due to the spraying procedure, only the characteristics of the mortar were accounted as a variable.

The porosity of the mortar is highly influenced by the type and the content of the set-accelerator admixture used during the spraying process. For this reason, two alkali-free set-accelerators were added in two contents at the nozzle. The aim is to achieve different levels of porosity. Another parameter that might affect the shear performance of SC is the degree of humidity of the material. In some application, the structure will remain in constant contact with water from the surroundings, being saturated during the service life. In others, the material will present a low degree of humidity. To evaluate the repercussion of this parameter, two extreme conditions were considered: dry and saturated. The dried samples were introduced in an oven at $50^{\circ} \mathrm{C}$ for 24 hours after which they were allowed to cool during 30 minutes before the test. The saturated samples remained under water during 24 hours until the execution of the test. 
296 The third parameter evaluated was the influence of the anisotropy of the sprayed layer induced

297 by the differential rebound. The rebound is particularly significant at the initial stage of the 298 spraying procedure, when the material impact directly at the substrate. Once a SC bed is formed 299 over the surface, the new particles are more likely to be retained, leading to a reduction in the 300 rebound (Agulló et al. 2009). Consequently, the SC layers closer to the surface of the panels are likely to present a smaller content of coarse aggregate than layers farther from the surface. To assess this potential anisotropy, the samples extracted from each core were identified depending on the distance from the surface as bottom (closer to the panel) and top (farther from the panel). The rough layer of the top part of the samples was cut to remove the irregularities (always less than $1 \mathrm{~cm}$ ) and, afterwards, the top and bottom surfaces were polished.

\subsubsection{Materials and concrete mix}

307

The composition of the SC was the same as the used for the experimental program with conventional concrete, shown in Table 2 . In addition to that, a set-accelerator admixture was added to simulate the typical composition of the SC similar to that applied in tunnels. In this case, two alkali-free set-accelerators, A1 and A2, were considered (see Table 2). The setaccelerator A1 was added in two different contents $5 \%$ and $7 \%$ by cement weight (bcw) in the mixes named SC1_LP and SC1_HP, respectively. The content of set-accelerator A2 was 7\% bcw in the mix named SC2_HP.

\subsubsection{Spraying setup and procedure}

The concrete was sprayed outdoors (see Fig.6a) with a MEYCO Altera compact wet-mix machine, which is an oil-hydraulically driven twin-piston pump with a peristaltic dosing unit for accelerators. A $10-\mathrm{m}^{3} / \mathrm{min}$ diesel air compressor was employed during the spraying. A concrete flow of $4.4 \mathrm{~m}^{3} / \mathrm{h}$ (equivalent to 20 strokes per minute) and an air pressure of 4 bars were used. The accelerator-dosing unit allowed a flow between 4.0 and $4.51 / \mathrm{min}$. The concrete was 
322 between the nozzle and the test panels was approximately $1.5 \mathrm{~m}$ (see Fig.6b).

323

324
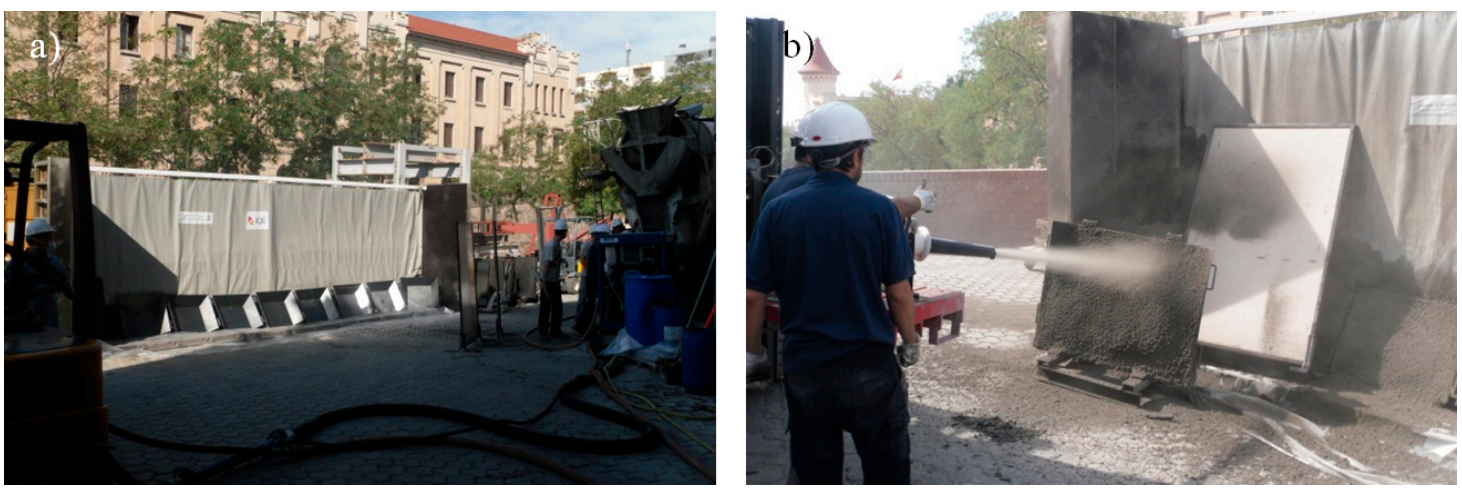

Fig.6 Special outdoor area to spray concrete: a) general view and b) detail of the spraying.

After the spraying, panels were covered with a burlap-curing blanket to avoid water evaporation from the surface until the unmoulding, 24 hours later. Subsequently, the pieces were piled together in outdoor conditions and covered with sacking. In order to maintain humidity, the pieces were wetted continuously. Cores were drilled the day after production from the pieces by means of a core extracting machine with $75 \mathrm{~mm}$ and $140 \mathrm{~mm}$ diameter drills. The distance between cores followed the minimum requirements defined in EN 14488-2:2007 (CEN 2007).

The rough face of the cores was cut to obtain a slenderness close to 2 for the specimens of 75 $\mathrm{mm}$ of diameter, which is the recommended slenderness by many standards for the compression test (CEN 2002, CPH 2008, fib 2013). Next, both surfaces of the samples were polished to maximize the contact and assure a good load distribution between the testing machines and the cores before being stored in a curing room at $20 \pm 2^{\circ} \mathrm{C}$ and $95 \pm 2 \%$ of relative humidity until the age of testing.

The analysis of the diameter of the notch is conducted on the mix SC1_LP by performing 4 tests for the samples with a diameter of $45 \mathrm{~mm}$ and 4 tests for the samples with $92 \mathrm{~mm}$ of diameter, both in dry conditions. The assessment of the degree of the humidity and the distance from the surface was assessed in the concrete mixes SC1_HP and SC2_HP by testing 12 samples in each 
case. Notice that from the 12 samples, 6 correspond to the bottom part of the original cylinder

342 and the other 6 were originally located in the top part of the cylinder.

\section{$343 \quad 4.1 .4$ Basic properties of the SC}

344 The assessment of the compressive strength, modulus of elasticity and porosity were performed

345 according with the same standards described in section 3.1.1. Cylindrical cores with a diameter 346 of $75 \mathrm{~mm}$ and a height of approximately $150 \mathrm{~mm}$ extracted from the sprayed panels were used.

347 The average results of these tests and their corresponding coefficient of variation are presented 348 in Table 5.

Table 5. Basic properties of sprayed concrete (SC)

350

\begin{tabular}{c|l|c|c|c}
\hline \multirow{2}{*}{ Properties } & \multicolumn{3}{|c}{ Average (CV) } \\
\cline { 3 - 5 } & & SC1_LP & SC1_HP & SC2_HP \\
\hline Mechanical & Modulus of elasticity (GPa) & $23.5(3.9 \%)$ & $21.1(9.2 \%)$ & $25.5(0,7 \%)$ \\
properties & Compressive strength (MPa) & $34.2(4.8 \%)$ & $33.6(6.6 \%)$ & $32.8(7.8 \%)$ \\
\hline Physical & Dry density (g/cm $\left.\mathrm{cm}^{3}\right)$ & $2.13(0.5 \%)$ & $2.07(4.6 \%)$ & $2.10(1.8 \%)$ \\
properties & Porosity (\%) & $14.6(3.9 \%)$ & $17.0(6.5 \%)$ & $16.9(6.6 \%)$ \\
\hline
\end{tabular}

351 By comparing the average properties of the SC mixes with those of the reference concrete (see

352 Table 3), it is clear that the spraying procedure leads to a material with higher porosity. Notice 353 that the average porosity for reference concrete is $12.0 \%$, whereas the average of all three SC mixes is $16.2 \%$. This represents an increase of $35 \%$ that affects other properties such as the compressive strength and the modulus of elasticity, which are significantly reduced in the case of the SC mixes.

According to the results from Table 5, the lowest porosity and highest mechanical properties were found in the mix with $5 \%$ bcw of set-accelerator A1, that is, SC1_LP. The increase in the dosage of set-accelerator (regardless of the type) led to an increase in porosity and a consequent decrease in the long-term mechanical properties. This is evident in mixes SC1_HP and SC2_HP.

Notice that the terms "LP" and "HP" used in the notation refer to the low and high level of porosities, respectively. The notation employed to designate each sample also includes the 
diameter of the notch (45 $\mathrm{mm}$ or $92 \mathrm{~mm}$ ), the location of the sample in the original specimens

365 ( $\mathrm{T}$ for top sample or B for bottom sample) and the humidity conditions (D for dry conditions or

$366 \mathrm{~S}$ for saturated conditions). A number is included to differentiate the samples with the same 367 properties and conditions. For example, the notation of a sample from the mix with $7 \%$ bcw of 368 set-accelerator A1, with a diameter of the notch of $45 \mathrm{~mm}$, cut from the upper position and 369 tested under dry conditions would be: SC1_HP_45_T_D_1.

\subsection{Influence of characteristics of SC on Shear Strength}

\subsubsection{Distance from the substrate}

372

Table 6 presents the average shear strengths of the samples and the coefficient of variation (CV) depending on their location regarding the surface of the panel (top or bottom). No clear trends on the influence of the distance from the substrate were found since the samples exhibit similar shear strengths regardless of their location. In terms of scatter, the samples located near the surface of the panel show higher values of coefficient of variation than the ones located at the top. Considering all the previous analyses, the possible differential rebound does not seem to affect significantly the shear response.

Table 6. Influence of the distance from the substrate in the shear strength of SC

\begin{tabular}{c|cc}
\hline \multirow{2}{*}{ Mixes } & \multicolumn{2}{|c}{ Shear strength in MPa (CV) } \\
\cline { 2 - 3 } & Top & Bottom \\
\hline SC1_LP & $14.10(1.9 \%)$ & $13.50(7.6 \%)$ \\
\hline SC1_HP & $12.27(6.6 \%)$ & $12.56(6.1 \%)$ \\
\hline SC2_HP & $12.80(4.9 \%)$ & $12.91(14.1 \%)$ \\
\hline
\end{tabular}

\subsubsection{Porosity}

Table 7 presents the shear strength for all SC samples with low porosity (LP) and high porosity (HP) listed from the sample with highest porosity (SC2_HP_45_B_D_7) to the lowest (SC1_HP_45_B_D_5). Furthermore, the results of porosity of the reference concrete (REF) studied in previous section is also included at the bottom of the table. Notice that all samples included in Table 7 correspond to dry conditions and a diameter of the notch of $45 \mathrm{~mm}$. 
range

\begin{tabular}{l|c|c|c|c}
\hline \multirow{2}{*}{ Specimen } & \multicolumn{2}{|c|}{ Individual values } & \multicolumn{2}{c}{$\begin{array}{c}\text { Average considering } \\
\text { porosity range }\end{array}$} \\
\cline { 2 - 5 } & $\begin{array}{c}\text { Porosity } \\
\text { (\%) }\end{array}$ & $\begin{array}{c}\text { Shear strength } \\
\text { (MPa) }\end{array}$ & $\begin{array}{c}\text { Porosity } \\
\text { (\%) }\end{array}$ & $\begin{array}{c}\text { Shear strength } \\
\text { (MPa) }\end{array}$ \\
\hline SC2_HP_48.5_B_D_7 & 19.0 & 10.83 & & \\
\hline SC1_HP_48.5_T_D_2 & 18.2 & 12.41 & 18.3 & 12.08 \\
\hline SC1_HP_48.5_T_D_8 & 18.0 & 13.00 & & \\
\hline SC1_HP_48.5_B_D_7 & 18.0 & 12.08 & & \\
\hline SC1_HP48.5_B_D_1 & 17.8 & 13.44 & & 12.81 \\
\hline SC2_HP_48.5_T_D_8 & 17.5 & 12.82 & 17.5 & \\
\hline SC2_HP_48.5_T_D_10 & 17.1 & 12.16 & & 13.01 \\
\hline SC1_HP_48.5_T_D_6 & 16.8 & 11.40 & & 13.46 \\
\hline SC2_HP_48.5_B_D_9 & 16.7 & 14.21 & 16.5 & \\
\hline SC2_HP_48.5_T_D_12 & 16.0 & 13.41 & & \\
\hline SC2_HP_48.5_B_D_11 & 15.9 & 13.68 & & 13.55 \\
\hline SC1_LP_48.5_T_D_6 & 15.6 & 13.91 & 15.5 & 13.89 \\
\hline SC1_LP_48.5_B_D_1 & 15.0 & 12.78 & & \\
\hline SC1_LP_48.5_B_D_5 & 14.9 & 14.22 & & \\
\hline SC1_LP_48.5_T_D_2 & 14.7 & 14.29 & 14.5 & \\
\hline SC1_HP_48.5_B_D_5 & 14.0 & 12.15 & & \\
\hline REF_48.5_D & - & - & 11.1 & 1 \\
\hline
\end{tabular}

389

390 The results shown in Table 7 reveal that the higher porosity of the mix, the lower the value of

391 shear strength. Such outcome was expected given that more porous matrices tend to exhibit

392 lower stress bearing capacity than denser matrices. These differences, as previously described,

393 are due to the type of set-accelerator used and its content, which influences the microstructure of

394 the material. No significant difference was found between the mixes with different accelerator

395 type and the same dosage. This indicates that the porosity is the main parameter governing the

396 shear strength.

397 Such strong correlation between both parameters is confirmed by the results in Fig.7, where the

398 shear strength is plotted against the porosity of all samples grouped by the type of mix:

399 SC2_HP_D, SC1_HP_D, SC1_LP_D and REF_D. The average grouped by porosity range from

400 Table 7 is also included in Fig.7 (see markers with black fill). The strong correlation between

401 the shear strength and the porosity of the mixes previously mentioned is confirmed by the high

$402 \quad \mathrm{R}^{2}$ of the trend line in Fig.7. 
403

404

405

406

407

408

409

410

411

412

413

414 The samples under dry conditions exhibit higher shear strength than the saturated samples. In

415 fact, these differences are $7.5 \%$ for the mix SC1_HP 48.5 and $5.2 \%$ for the mix SC2_HP 48.5 .

416 This is consistent with the literature about conventional concrete, which reports that under

417 saturated conditions the compressive strength is $5 \%$ lower than in dry conditions. This may be

Fig. 7 Shear strength vs. porosity (samples with diameter of $48.5 \mathrm{~mm}$ and dry conditions; for average values see markers with black fill).

\subsubsection{Humidity}

The influence of the degree of humidity of the SC mixes on the shear response is evaluated in the mixes with high porosity since it should be more evident in the presence of more pores. Table 8 presents the average shear strengths of all samples tested under dry and saturated conditions.

Table 8. Influence of humidity for SC1_HP_48.5 and SC2_HP_48.5.

\begin{tabular}{|c|c|c|c|c|c|}
\hline \multirow{2}{*}{\multicolumn{2}{|c|}{$\begin{array}{l}\text { Humidity } \\
\text { conditions }\end{array}$}} & \multicolumn{2}{|c|}{ SC1_HP_48.5 } & \multicolumn{2}{|c|}{ SC2_HP 48.5} \\
\hline & & Top & Bottom & Top & Bottom \\
\hline \multirow{2}{*}{ Saturated } & $\begin{array}{l}\text { Average per } \\
\text { location }(\mathrm{CV})\end{array}$ & $\begin{array}{l}11.45 \\
(5.9 \%)\end{array}$ & $\begin{array}{c}11.62 \\
(5.4 \%)\end{array}$ & $\begin{array}{c}12.64 \\
(7.0 \%)\end{array}$ & $\begin{array}{c}11.78 \\
(12.2 \%)\end{array}$ \\
\hline & $\begin{array}{c}\text { Average per humidity } \\
\text { Conditions }(\mathrm{CV})\end{array}$ & \multicolumn{2}{|c|}{$11.54(5.1 \%)$} & \multicolumn{2}{|c|}{$12.21(9.5 \%)$} \\
\hline \multirow[t]{2}{*}{ Dry } & $\begin{array}{l}\text { Average per } \\
\text { location }(\mathrm{CV})\end{array}$ & $\begin{array}{l}12.27 \\
(6.6 \%)\end{array}$ & $\begin{array}{c}12.56 \\
(6.1 \%)\end{array}$ & $\begin{array}{l}12.80 \\
(4.9 \%)\end{array}$ & $\begin{array}{l}12.91 \\
(14.1 \%)\end{array}$ \\
\hline & $\begin{array}{l}\text { Average per humidity } \\
\text { conditions }(\mathrm{CV})\end{array}$ & \multicolumn{2}{|c|}{$12.41(5.8 \%)$} & \multicolumn{2}{|c|}{$12.85(9.5 \%)$} \\
\hline
\end{tabular}

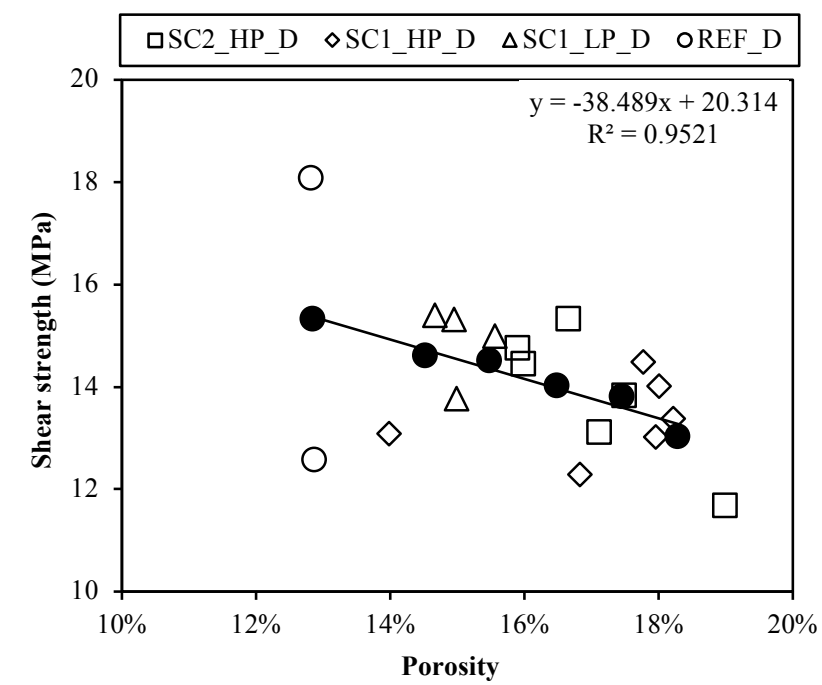


418 attributed to the weakening of the bond between the phases of hydrated cement and the

419 reduction of interstitial forces due to the presence of water.

420

421

422

423

424

425

426

427

428

429

430

431

432

\subsubsection{Diameter of the notch}

Table 9 presents all values of shear strength from samples with $48.5 \mathrm{~mm}$ and $88 \mathrm{~mm}$ notch as well as their average and coefficient of variation. The average values indicate that the shear strength for samples with $48.5 \mathrm{~mm}$ of diameter is $36.9 \%$ higher than the strength for the samples with $88 \mathrm{~mm}$ of diameter. Again, such outcome may be attributed to the bigger confinement provided by the external crown of the sample.

Table 9. Influence of the diameter of the notch (SC1_LP)

\begin{tabular}{c|c|c|c|c}
\hline \multirow{2}{*}{ Location } & \multicolumn{2}{|c|}{$\mathbf{4 8 . 5} \mathbf{~ m m}$} & \multicolumn{2}{c}{$\mathbf{8 8} \mathbf{~ m m}$} \\
\cline { 2 - 5 } & $\begin{array}{c}\text { Shear strength } \\
\text { (MPa) }\end{array}$ & $\begin{array}{c}\text { Average per } \\
\text { location (CV) }\end{array}$ & $\begin{array}{c}\text { Shear strength } \\
\text { (MPa) }\end{array}$ & $\begin{array}{c}\text { Average per } \\
\text { location (CV) }\end{array}$ \\
\hline \multirow{2}{*}{ Top } & 14.29 & 14.10 & 8.97 & 9.64 \\
& 13.91 & $(1.9 \%)$ & 10.31 & $(9.8 \%)$ \\
\hline \multirow{2}{*}{ Bottom } & 12.78 & 13.50 & 10.61 & 10.51 \\
& 14.22 & $(7.6 \%)$ & 10.41 & $(1.3 \%)$ \\
\hline Average per diameter (CV) & \multicolumn{2}{|c|}{$13.80(5.1 \%)$} & \multicolumn{2}{c}{$10.08(7.4 \%)$} \\
\hline
\end{tabular}

\section{COMPARISON OF SPRAYED CONCRETE WITH CONVENTIONAL CONCRETE}

In this section the results obtained in the different stages of the experimental program for conventional concrete and sprayed concrete are compared in Table 10. It should be highlighted that there are small differences in the dimensions of the specimens used to characterize the mechanical performance of the materials. These small differences are due to the casting procedure and the method employed to obtain the specimens (moulded or drilled from panels).

Their influence in the results is assumed to be negligible.

Table 10. Shear strength of reference concrete and sprayed concrete mixes

\begin{tabular}{c|c|c}
\hline \multirow{2}{*}{ Mixes } & \multicolumn{2}{|c}{$\begin{array}{c}\text { Shear strength (MPa) } \\
\text { (Average (CV)) }\end{array}$} \\
\cline { 2 - 3 } & $\begin{array}{c}\text { Ø48.5 mm and } \\
\text { dry conditions }\end{array}$ & $\begin{array}{c}\text { Ø88 mm and } \\
\text { dry conditions }\end{array}$ \\
\hline SC1_LP & $13.80(5.1 \%)$ & $10.08(7.4 \%)$ \\
\hline SC1_HP & $12.41(5.8 \%)$ & Not evaluated \\
\hline SC2_HP & $12.85(9.5 \%)$ & Not evaluated \\
\hline REF & $13.89(19.7 \%)$ & $10.48(16.9 \%)$ \\
\hline
\end{tabular}


437 In general, the shear strength of the reference concrete (REF) is higher than for sprayed concrete 438 mixes. The differences are only $0.7 \%$ for the mix SC1_LP, $11.9 \%$ for the mix SC1_HP and $4398.1 \%$ for the mix SC2_HP, in dry conditions and for a diameter of $48.5 \mathrm{~mm}$. These results 440 reveal that, despite the spraying procedure, the SC mixes achieve shear strengths that are close 441 to that of the reference concrete. This is observed particularly in the mixes with low porosity 442 (LP). In fact, from the previous analyses, it may be derived that the main factor for the reduction 443 in shear strength in the SC mixes is the porosity of the matrix. Notice that spraying the concrete 444 may increase the porosity of the mix up to $64.8 \%$ (according to Table 7), depending on the type 445 and content of set-accelerator used for the spraying procedure.

\section{CONCLUSIONS}

447 The present study focused on the assessment of shear behaviour of SC through and adaptation of Luong tests. The main conclusions derived from this work are presented subsequently.

- The proposed testing method has proven to be compatible with the conditions results

- The load distribution has great repercussion on the failure mode of the specimens in the Luong test. The application of loads distributed over the whole surface leads to an inclined cracked plane that suggests the influence of normal stresses in addition to tangential stresses. On the contrary, the application of concentrated loads produces a cracking governed mainly by shear stresses and a failure that occurs within the weak area defined by the notch. For this reason, the setup with the concentrated load distribution is recommended. 
- The diameter of the notch influences significantly the value of the shear strength due to the confinement effect provided by the external crown of concrete outside the perimeter of the notch. The smaller the diameter of the notch, the greater the confinement and thus the shear strength. A diameter of $48.5 \mathrm{~mm}$ is recommended based on the experimental results.

\section{ACKNOWLEDGEMENTS}

486 The authors of this document wish to show their gratitude for the economic support received through the project RTC-2015-3185-4 (MAPMIT), co-funded by the Ministerio de Economía y Competitividad of Spain in the Call Restos-Colaboración 2015 and by the European Union 
490 innovation and high quality research. Likewise, the authors acknowledge Industrias Quimicas

491 del Ebro (IQE) and, in particular, Jorge Pérez, Ángel Rueda and Miguel Cano for their technical 492 support. The authors also thank Ricardo Mateo for his collaboration during the experimental 493 program.

\section{REFERENCES}

495 Agulló, L.; García, T.; Aguado, A.; Yubero, E. Evaluation of isotropy in wet-mix sprayed concrete, Materiales de Construcción, 59, 295 (2009), 19-39, doi:10.3989/mc.2009.44607

497 Allos, A.E. Shear Transfer in Fibre Reinforced Concrete, in Fiber Reinforced Cement and 498 Concretes: Recent Developments (Eds.: R.N. Swamy and B. Barr), Elsevier Applied Science, 499 London, 1989, pp.146-156.

500 Barr, B. The Fracture Characteristics of FRC Materials in Shear, in Fiber Reinforced Concrete, 501 Properties and Applications (Eds.: S.P. Shah, G.B. Batson), ACI, Detroit, USA, 1987, pp. 2750253.

503 Barr B.; Derradj M. Numerical study of a shear (Mode II) Type test specimen geometry, Eng. 504 Fract. Mechanics, 1990, 35(1/2/3): 171-180.

505 CEDEX. NLT-382/08 Evaluación de la adherencia entre capas de firme, mediante ensayo de 506 corte, Madrid, 2008.

507 CEN. Design of concrete structures. Part 1: General Rules for buildings. Eurocode 2, European 508 Prestandard, ENV 1992-1. European Committee for Standardization, Brussels, 2002.

509 CEN. EN 12620:2002. Aggregates for concrete, European Committee for Standardization, $510 \quad$ Brussels, 2002.

511 CEN. EN 12390-3:2009. Testing hardened concrete - Part 3: Compressive strength of test 512 specimens, European Committee for Standardization, Brussels, 2009.

513 CEN. EN 12390-7:2009. Testing hardened concrete - Part 7: Density of hardened concrete, 514 European Committee for Standardization, Brussels, 2009.

515 CEN. EN 12390-13:2014. Testing hardened concrete - Part 13: Determination of secant 516 modulus of elasticity in compression, European Committee for Standardization, Brussels, 2014. 
517 CEN. EN 14488-1:2006. Testing sprayed concrete - Part 1: Sampling fresh and hardened 518 concrete, European Committee for Standardization, Brussels, 2006.

519 CEN. EN 14488-2:2007. Testing sprayed concrete - Part 2: Compressive strength of young 520 sprayed concrete, European Committee for Standardization, Brussels, 2007.

521 CPH. EHE-08 Instrucción del Hormigón Estructural, Cominisión Permanente del Hormigón, 522 Ministerio de Fomento, Madrid, 2008.

523 fib. Model Code for Concrete Structures 2010, Fédération International du Béton, Laussane, 5242013.

525 Galobardes, I.; Cavalaro, S.H.P.; Aguado, A.; García, T. Estimation of the modulus of elasticity 526 for sprayed concrete, Constr. Build. Mater., 53, (2014) 48-58, doi : $527 \quad 10.1016 /$ j.conbuildmat.2013.11.046.

528 Iosipescu N. New accurate procedure for single shear testing of metals. Journal of Mater., 2(3), 529 (1967) 537-566.

530 JSCE-SF6, Method of Test for Shear Strength of Steel Fiber Reinforced Concrete (SFRC), 531 Japan Society of Civil Engineers, Tokyo, 1990, pp 67-69.

532 Luong, M.P. Tensile and shear strengths of concrete and rock. Eng. Fract. Mech., 35(1/2/3), 533 (1990) 127-135.

534 Miro R.; Perez. F.; Borrás, J.M. Evaluation of the Effect of Tack Coats. LCB Shear Test, in 535 Proceedings of Sixth International RILEM Symposium on Performance Testing and Evaluation 536 of Bituminous Materials (Eds.: M.N. Partl), Zurich, 2003, pp.550-556

537 Miro, R.; Martinez, A.; Perez, F. Evaluation of the effect of heat-adhesive emulsions for tack 538 coats with shear test from the road research laboratory of Barcelona. Transportation Research 539 Record, 2006, no. 1970, p. 64.

540 Mirsayah, A.; Banthia, N.. Shear Strength of Steel Fiber-Reinforced Concrete. ACI Mater. 541 Journal, 99, (2002), 473-479.

542 Montenegro, O. I.; Sfer, D.; Carol, I. Análisis de la falla del hormigón en modo mixto. 543 Mecánica Computacional, 2008, Volumen XXVII, pp. 1365-1373. 
544 Salvador, R. P.; Cavalaro, S.H.P.; Segura, I.; Figueiredo, A.D.; Pérez, J. Early age hydration of

545 cement pastes with alkaline and alkali-free accelerators for sprayed concrete, Constr. Build.

546 Mater., Volume 111, (2016a), pp. 386-398, ISSN 0950-0618, doi:

$547 \quad$ 10.1016/j.conbuildmat.2016.02.101.

548 Salvador, R. P.; Cavalaro, S.H.P.; Cano, M.; Figueiredo, A.D. Influence of spraying on the early

549 hydration of accelerated cement pastes, Cem. Con. Res., Volume 88, (2016b), pp. 7-19, ISSN

550 0008-8846, doi: 10.1016/j.cemconres.2016.06.005.

551 Schlangen E. Experimental and numerical analysis of fracture processes in concrete. Doctoral

552 Thesis, Delft University of Technology, Delft, 1993.

553 Segura, L.; Aguado, A. Bi-layer diaphragm walls: Evolution of concrete-to-concrete bond 554 strength at early ages, Constr. Build. Mater., 31, (2012), 29-37, doi:

$555 \quad 10.1016 /$ j.conbuildmat.2011.12.090

556 Shah S.; Swartz S.; Ouyang C. Fracture Mechanics of concrete: Applications of Fracture

557 Mechanics to Concrete, Rock, and Other Quasi-Brittle Materials. John Wiley \& Sons, New $558 \quad$ York, 1995, pp. 552. 